periodicals where these are not available and where they are not more suitably taken and made available by another library. The policy regarding acquisition of periodicals for loan will be closely related to that for the purchase of learned society publications. It is also intended to build up a collection of specimen copies of new periodicals. Mr. Filon stresses that these changes imply no changes in the rules for the inter-lending work of the Library or in its work for adult classes.

\section{Index Chemicus}

A NEW journal entitled Index Chemicus has been published by the Institute for Scientific Information, 1122 Spring Garden Street, Philadelphia (annual subscription rates: educational foundations, 250 dollars; industrial and Government agencies, etc., 500 dollars). The publication is a monthly index of new compounds reported in the literature and claims to give information within thirty days of its first appearance. The first number reports more than 3,700 newly synthesized organic compounds. The production is in the hands of a staff of experienced organic chemists, and the preparation uses both manual and machine methods for handling chemical information. A system of checking to ensure accuracy is in use. The text lists chemical names, structural diagrams and molecular formulæ, as well as complete bibliographical information including article title, authors' institutions, addresses, and original journal references for each compound. Indexes will be issued quarterly and annually. Each entry is numbered and there is an inserted author index referring to these numbers. It is noticed that Japanese and Russian literature is extensively covered.

There is no doubt that this new publication will greatly facilitate the work of research chemists in the field of organic chemistry. In other abstract journals there is a serious time lag between the publication of the material and the appearance of the abstract, and particularly in the publication of indexes. The amount of information which can be extracted from the Index is, however, very limited, but enough is probably given to enable a chemist to know if the publication listed is likely to be of interest to him. Particulars of prices, etc., also a booklet and specimen pages, can be obtained from the Institute.

\section{Nuclear Engineering Abstracts}

THE appearance of yet another abstracting journal is an event which it is natural to regard with some suspicion. However, the practice of nuclear engineering involves the drawing together of so many different sciences that there has been a growing need for a journal which attempts to cover the whole field. Nuclear Engineering Abstracts sets out to provide informative abstracts of all the important publications which are relevant to the theory or practice of nuclear engineering ; the coverage is wider than that of many abstracting journals, since newspapers and house journals are included, when appropriate, in addition to the usual periodicals, patents and reports. The standard set by the first issue of the new journal is high ; the layout is good, so also are the indexing and cross-referencing. If this standard can be maintained in succeeding issues, Nuclear Engineering Abstracts will be essential reading for anyone taking a real interest in the field (Nuclear Engineering $\mathrm{Ab}$ stracts, 1, No. 1 ; July 1960. Pp. 100. London: Silver Fnd Documentary Publications, Ltd., 1960. Annual subscription covering four issues, post paid, $£ 668$.; 18.50 dollars. Single copies, if available, post paid, £1 12 s. $6 d$. ; 4.75 dollars).

\section{Scientific Papers of the Meteorological Office}

"Airborne Measurements of Latitudinal Variation of Frost-point Temperature and Wind" is the subject of the first number of a new series entitled "Scientific Papers" to be published by the Meteorological Office (Air Ministry: Meteorological Office. Scientific Paper No. 1. Pp. ii +30 . (M.O. 664.) (London: H.M. Stationery Office, 1960.) 3s.6d.net). This series replaces the former "Professional Notes" and "Meteorological Reports", and like them each number will contain one paper. It will give accounts of research work carried out in the Office. It is printed on paper more than an inch wider than its predecessors in order to allow more space for the diagrams which are an important foature of most meteorological papers. Accounts of the most important investigations will, however, continue to appear in the "Geophysical Memoirs" series. This first issue, by N. C. Helliwell, summarizes and discusses observations of the elements quoted made by the Meteorological Research Flight in the lower stratosphere on six days in the summer of 1956 and three in March 1957 between Minorca and the Norwegian Sea near the Arctic Circle. The frost-point, giving a measure of the humidity, showed little variation with latitude. Jet streams were traversed on some flights, and the horizontal wind-shear in them was measured. Clearair turbulence was, as expected, encountered in association with some jet streams, but it was also encountered at places where no explanation for it could be found. The temperature observations on two flights were such as to suggest that tropospherie fronts were continued into the stratosphere.

\section{Environment and Culture in Southern Rhodesia}

Roger Summers, curator of the Museum at Bula wayo, Southern Rhodesia, has published an interesting paper on the relationships of environment to past cultures in that country (Proc. Amer. Phil. Soc., 104 , No. 3 ; June 15, 1960). In arguing from the present to the past, changes in climate naturally have to be remembered, but the physical map and the geology of the region have remained constant. No less than twenty-three distribution maps are given, showing such things as the modern vegetation pattern and what it would be with various percentages of the present rainfall. Other maps show the distribution of the prehistoric cultures, as well as of the rock-shelter art and the ancient mine workings. Why did some early cultures shun areas where Mopane forests would be growing? The answer is probably because the tsetse fly Glossina morsitans would have made cattle breeding impossible in those districts. The various possible invasion routes depend to a large extent on the 'lay-out' of the country, and peoples coming in from outside have, of course, greatly influenced past history. Actually, Southern Rhodesia can be shown to have been both a cradle and a corridor. Again and again not enough attention has been paid to the relationship of various culture groups to their environment, both climatic and geological, when the past history of a country is being studied. Roger Summers is to be congratulated in having so successfully followed in the footsteps of Sir Cyril Fox in producing for Southern Rhodesia what Sir Cyril did in his "Personality of Britain". 